\title{
Mathematical Modeling of Sucrose Hydrolysis with Product and Substrate Inhibition
}

\author{
Brunella Ascione, Rino Apicella, Vittorio Romano* \\ Department of Industrial Engineering, University of Salerno, Fisciano, Italy \\ Email: *vromano@unisa.it
}

How to cite this paper: Ascione, B., Apicella, R. and Romano, V. (2020) Mathematical Modeling of Sucrose Hydrolysis with Product and Substrate Inhibition. Engineering, 12, 280-289. https://doi.org/10.4236/eng.2020.124023

Received: March 21, 2020

Accepted: April 24, 2020

Published: April 27, 2020

Copyright (C) 2020 by author(s) and Scientific Research Publishing Inc. This work is licensed under the Creative Commons Attribution International License (CC BY 4.0).

http://creativecommons.org/licenses/by/4.0/

\section{(c) (i) Open Access}

\begin{abstract}
In this work, the enzymatic hydrolysis reaction of sucrose through invertase under unsteady-state conditions has been investigated. The aim is to evaluate the inhibition phenomena influence on the reaction rate and, then, on the concentration and temperature profiles by simulating the process in a tubular reactor, varying the enzyme concentration and the reactant mixture velocity. The transport phenomena considered during the enzymatic hydrolysis process have been described by means of unsteady-state momentum, mass and energy balance equations, taking into account molecular and convective transport and generation terms. Interpretation and discussion of the results obtained by FEM resolution of PDEs involved allow to understand the relevance of the operating parameters.
\end{abstract}

\section{Keywords}

Sucrose Hydrolysis, Product and Substrate Inhibitions, Transport

Phenomena, Finite Element Method

\section{Introduction}

Sucrose is often hydrolyzed to produce invert sugar, a mixture of its two monosaccharides, glucose and fructose, as the latter shows a higher sweetening power respect to the sucrose itself [1]. Sucrose is hydrolyzed with either acidic or enzymatic hydrolysis [2]. The latter, carried out with invertase enzyme, is preferred to the acidic one because it prevents the formation of polluting colored compounds and the resulting sugar has a more pleasant taste. Invertase, called disaccharidase or $\beta$-fructofuranosidase, is a protein that belongs to the class of hydrolytic enzymes and it can be produced by many microorganisms that can use sucrose as a nutrient [3]. Commercially, the invertase is mainly biosynthesized by yeast strains of Saccharomyces cerevisiae [4] or Saccharomyces carlsbergensi. 
The kinetics of this reaction has been studied in different works, in particular the activity of the invertase, the inhibitory effects caused by the products and/or the substrate, and/or other factors such as viscosity and water concentration and sucrose diffusion were analyzed. All these equations were derived from Michaelis-Menten kinetics, taking into account inhibitory effects. D. Combes and P. Monsan found that the increase in viscosity does not affect either the efficiency or the activity of the invertase [5]. Kertesz realized the importance of water concentration as a determining parameter in the hydrolysis rate of sucrose by invertase [6]. Also, by considering the reduction in water concentration throughout the reaction, Bowski, Saini, Ryu \& Vieth showed that the reaction rate gradually increases by increasing the sucrose concentration until a certain value, after which the reaction velocity decreases with increasing sucrose concentration [7].

From the above discussions, it appears that preserving the invertase performance in all its applications is of great importance. The researches showed that the most important and influential parameters in this regard are $\mathrm{pH}$ of the reaction medium, temperature and the cumulative effect where all of these are a function of time in which the enzyme is used. Temperature slightly increases due to the exothermicity of the reaction (heat of reaction $\Delta H_{r}=-14930 \mathrm{~J} / \mathrm{mol}$ [8]).

Simulations under unsteady state conditions of the transport phenomena involved in the enzymatic hydrolysis process in a tubular reactor are performed. Then, evaluation of the influence of enzymatic concentration and reactant mixture flow rate is carried on. This can be useful for a better understanding of the process, improving industrial applications.

\section{Mathematical Model}

Sucrose (S) enzymatic hydrolysis into glucose (G) and fructose (F) has been modeled as an unsteady-state process, providing a pressure drop between inlet and outlet sections of a tubular reactor of radius $R=0.04 \mathrm{~m}$ and length $L=0.3$ $\mathrm{m}$, causing a laminar flow with average velocity $v_{m}$. In such a way, besides the time dependence, only the axial component of fluid velocity results to be different from zero and dependent on the radial direction $v_{z}(r, t)$, while the sucrose concentration and the temperature both on the radial and axial direction, $C_{s}(r, z, t)$ and $T(r, z, t)$. A scheme of the physical system is reported in Figure 1.

Unsteady-state momentum, mass and energy equations, including molecular and convective transport, developed on a differential volume $\Delta V=2 \pi r \Delta r \Delta z$, considering a cylindrical coordinate system $(r, \theta, z)$ [9], are reported in Table 1.

As initial condition, the fluid is still, with a sucrose concentration equal to zero, and presents uniform temperature. As boundary conditions for the radial direction, the symmetry condition respect to the $z$-axis is considered, while no-slip, impermeability and thermal insulation conditions of the reactant mixture are applied at the wall, respectively for momentum, mass and energy equations. For 


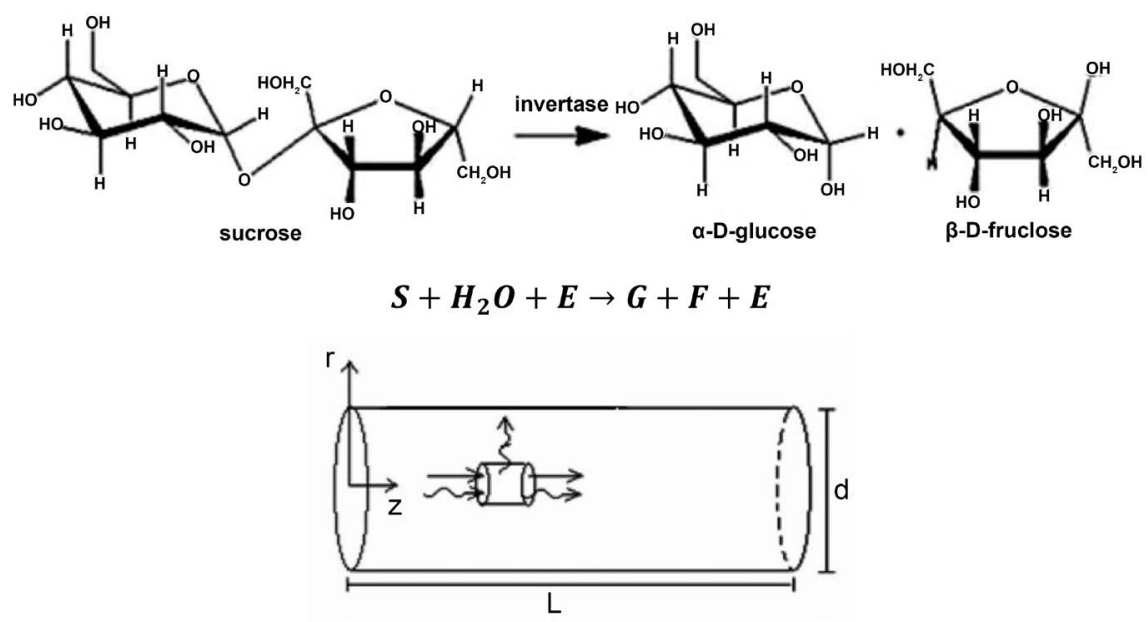

Figure 1. Physical system.

Table 1. Equations system.

$$
\begin{aligned}
& \mu\left(\frac{1}{r} \frac{\partial}{\partial r}\left(r \frac{\partial v_{z}}{\partial r_{s}}\right)\right)+\frac{P_{\text {in }}-P_{\text {out }}}{L}=\rho \frac{\partial v_{z}}{\partial t} \\
& -2 v_{m}\left[1-\left(\frac{r}{R}\right)^{2}\right] \frac{\partial C_{s}}{\partial z}+\mathfrak{D} \frac{\partial^{2} C_{s}}{\partial z^{2}}+\mathfrak{D}\left[\frac{1}{r} \frac{\partial}{\partial r}\left(r \frac{\partial C_{s}}{\partial r}\right)\right]-\left(-r_{s}\right)=\frac{\partial C_{s}}{\partial t} \\
& -2 \rho c p v_{m}\left[1-\left(\frac{r}{R}\right)^{2}\right] \frac{\partial T}{\partial z}+k \frac{\partial^{2} T}{\partial z^{2}}+k\left[\frac{1}{r} \frac{\partial}{\partial r}\left(r \frac{\partial T}{\partial r}\right)\right]-\left(-r_{s}\right)\left(-\Delta H_{r}\right)+16 \mu v_{m}^{2} \frac{r^{2}}{R^{4}}=\rho c p \frac{\partial T}{\partial t} \\
& \text { where }\left(-r_{s}\right)=\frac{K_{3} C_{E} C_{S}}{k_{m}\left(1+\frac{C_{s 0}-C_{S}}{k_{I}}\right)+C_{S}+\frac{C_{S}^{2}}{k_{I I I}}}
\end{aligned}
$$

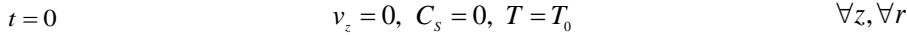

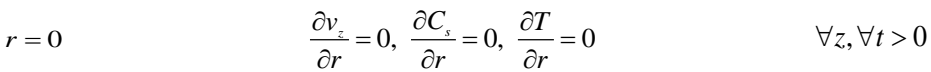

$$
\begin{aligned}
& r=R \quad v_{z}=0, \frac{\partial C_{s}}{\partial r}=0, \frac{\partial T}{\partial r}=0 \quad \forall z, \forall t>0
\end{aligned}
$$

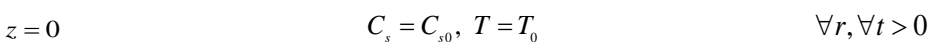

$$
\begin{aligned}
& \begin{array}{lll}
z=L & \frac{\partial C_{s}}{\partial z}=0, \frac{\partial T}{\partial z}=0 & \forall r, \forall t>0
\end{array}
\end{aligned}
$$

the $z$ direction, uniform sucrose concentration and temperature of the reactant mixture in the inlet and Danckwerts's condition in the outlet section are imposed.

\section{Materials and Methods}

The simulations were carried out using the thermodynamic, transport and kinetics parameters values reported in Table 2 .

The value of $834 \mathrm{mM}$, corresponding to $30 \%$ by weight, has been used for the inlet sucrose concentration. To solve the partial differential equations with initial and boundary conditions of mathematical model, COMSOL Multiphysics code 
has been used, based on a Finite Elements Method (FEM). According the FEM approach, the tubular reactor has been divided in subdomains (Finite Elements) assembled like in Figure 2.

Table 2. Values of parameters used in the simulations.

\begin{tabular}{ccc}
\hline$k$ & 0.6 & {$[\mathrm{~W} /(\mathrm{m} \cdot \mathrm{K})]$} \\
$c_{p}$ & 3510 & $[\mathrm{~J} / \mathrm{kg} \cdot \mathrm{K})]$ \\
$\rho$ & 1100 & {$\left[\mathrm{~kg} / \mathrm{m}^{3}\right]$} \\
$\mu$ & $1.8 \times 0^{-3}$ & {$[\mathrm{~Pa} \cdot \mathrm{s}]$} \\
$\mathfrak{D}$ & $4.9 \times 10^{-10}$ & {$\left[\mathrm{~m}^{2} / \mathrm{s}\right]$} \\
$k_{m}$ & 2.8 & {$\left[\mathrm{~mol} / \mathrm{m}^{3}\right]$} \\
$k_{3}$ & 3.27 & {$[\mathrm{~mol} /(\mathrm{kg} \cdot \mathrm{s})]$} \\
$k_{\mathrm{I}}$ & 8.7 & {$\left[\mathrm{~mol} / \mathrm{m}^{3}\right]$} \\
$k_{\text {III }}$ & 400 & {$\left[\mathrm{~mol} / \mathrm{m}^{3}\right]$} \\
\hline
\end{tabular}

\begin{tabular}{|l|l|}
\hline \\
\hline \\
\hline \multicolumn{1}{|l|}{} \\
\hline Mesh vertices \\
\hline Triangle elements \\
\hline Quadrilateral elements \\
\hline Edge elements & 0.15 \\
\hline Vertex elements & 3574 \\
\hline Number of elements & 5921 \\
\hline Minimum element quality & 430 \\
\hline Average element quality & 365 \\
\hline Element area ratio & 4 \\
\hline Mesh area & 6351 \\
\hline
\end{tabular}

Figure 2. Mesh type and mesh statistics.

\section{Results and Discussion}

In Figure 3, time parametric line graphs of velocity (a), substrate concentration (b) and temperature (c) are reported against $r$ and $z$ coordinates $[\mathrm{cm}]$, with $V_{m}=1 \mathrm{~cm} / \mathrm{s}$ and $C_{E}=15 \mathrm{~kg} / \mathrm{m}^{3}$.

In the first 70 seconds, it can be observed that in the output section the substrate concentration profiles are practically zero, since the velocity profiles have not yet reached the values that would allow the particles to go through the entire reactor length; consequently, in the outlet section, the reaction does not take place and, therefore, the temperature profile in this time interval is practically constant and equal to the value $T_{0}=303 \mathrm{~K}$. 


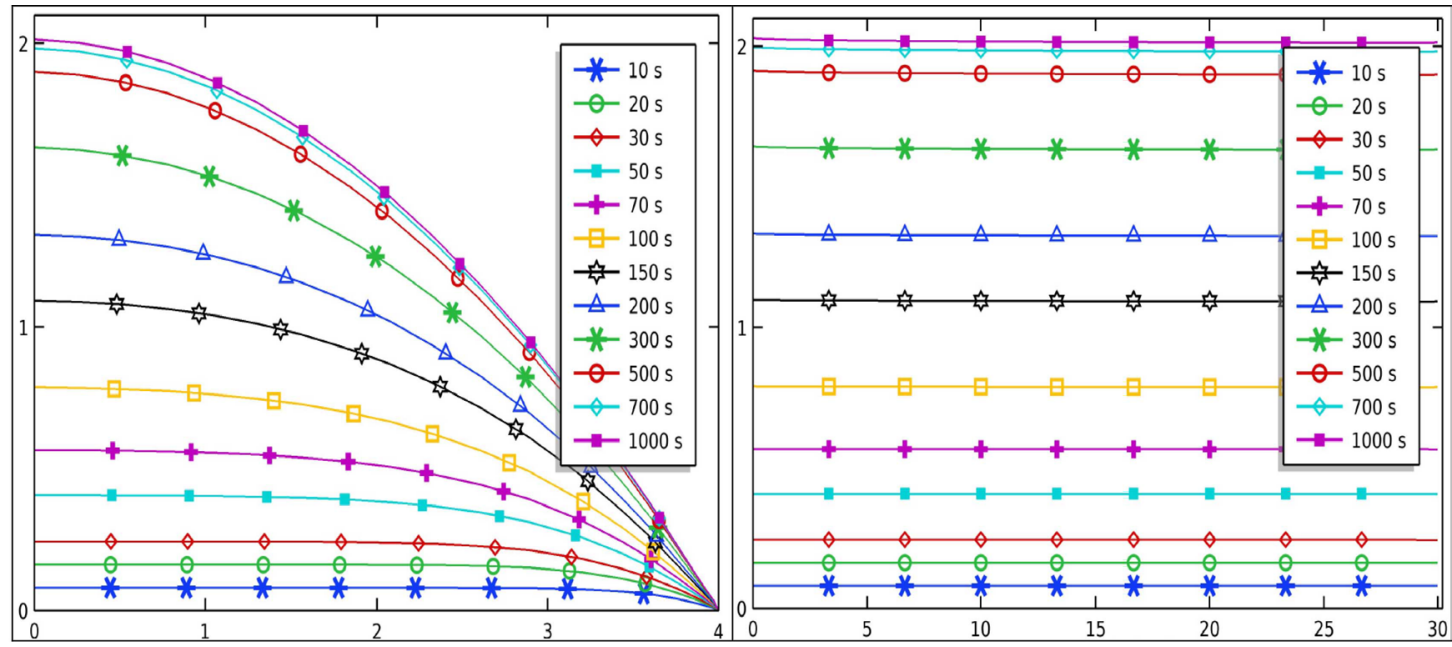

(a)
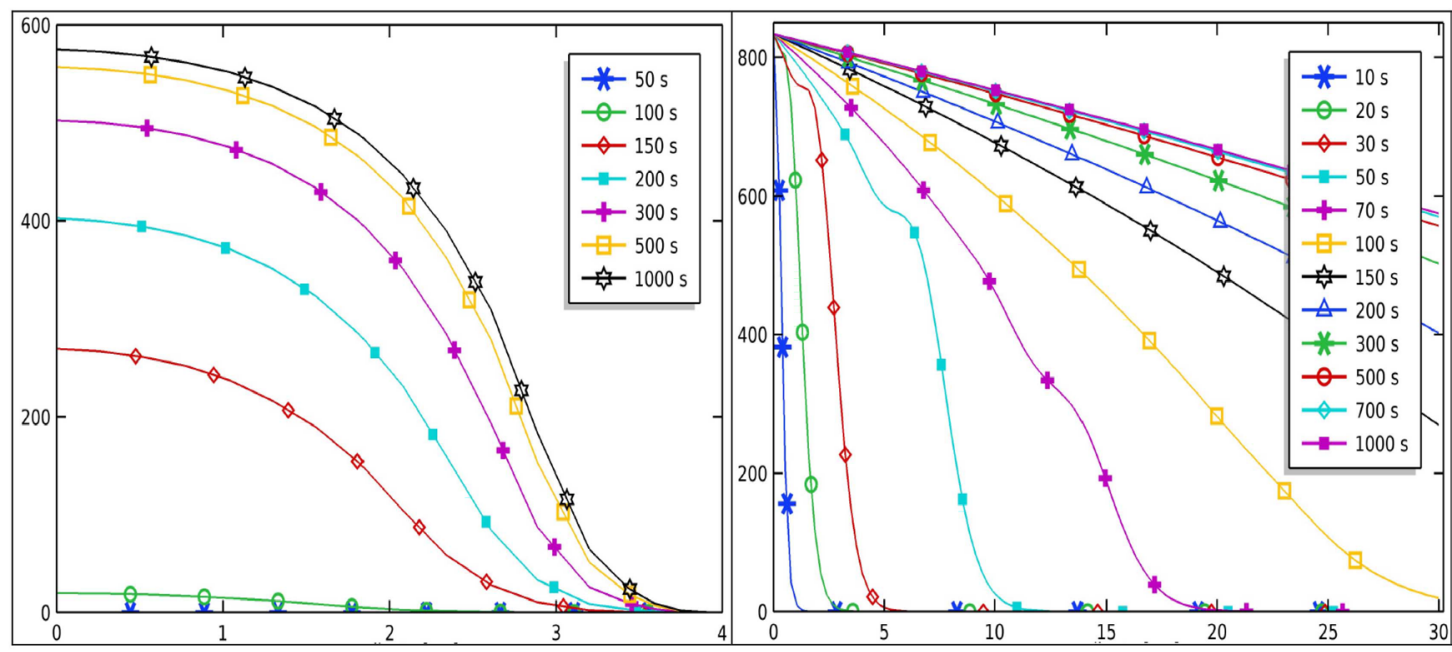

(b)

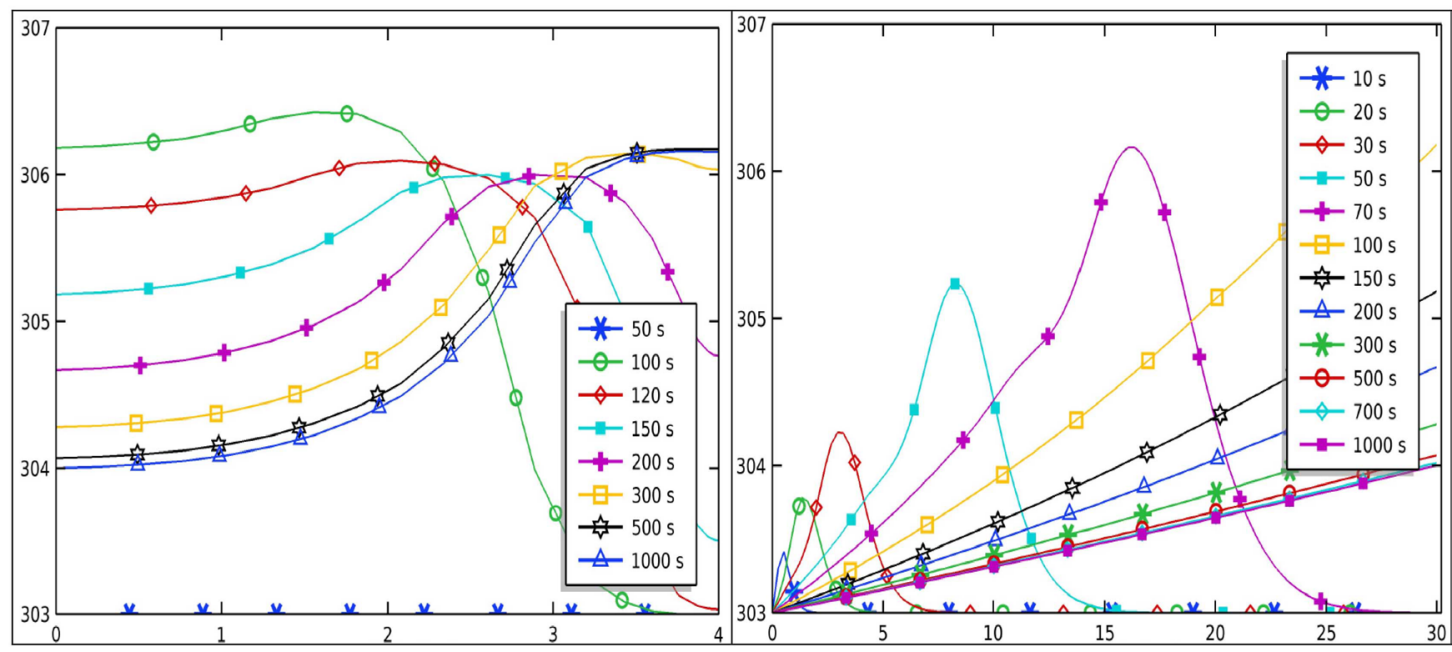

(c)

Figure 3. (a) Time parametric line graphs of velocity $v_{z}(r, z=L, t)$ and $v_{z}(r=0, z, t)$; (b) Time parametric line graphs of substrate concentration $C_{S}(r, z=L, t)$ and $C_{S}(r=0, z, t)$; (c) Time parametric line graphs of temperature $T(r, z=L, t)$ and $T(r=0, z, t)$ with $r, z[\mathrm{~cm}]$. 
From 80 to 100 seconds, the velocity profiles continue to increase, more to the axis and less towards the reactor wall, while the substrate concentrations and temperatures at the reactor outlet both decrease from the center towards the reactor wall. The concentration profile in the outlet section of the reactor decreases because a lower concentration arrives and it is not due to a higher conversion of the substrate, which would have caused a temperature rise, due to the exothermicity of the reaction.

In the time interval between 100 and 200 seconds, in the outlet section, the velocity profiles continue to evolve, the concentration profiles consolidate the decreasing trend, while the temperature profiles change, showing a maximum that, over time, moves towards the reactor wall. This maximum can be explained on the basis of the different velocities of the fluid elements: particles near the axis are able to reach the outlet section, reacting and developing heat; particles near the wall are too slow to run across the whole tube and for this reason they can't have reacted in the outlet section and heat has not been released. In particular, at $t=$ $200 \mathrm{~s}$, the velocity and substrate concentration profiles in the outlet section clearly decrease along the radius, while the temperature shows the maximum value for $r$ $=0.03 \mathrm{~m}$ and then it decreases up to the reactor wall. Right now, the reactant mixture between the axis and $75 \%$ of the reactor radius has a velocity that is sufficient to reach the outlet section and to react, with increasing residence times due to the decreasing velocity. Therefore, while the concentration decrease and the temperature increase up to the position $r=0.03 \mathrm{~m}$ denote a greater conversion, the following concentration drop, according to the temperature decrease up to the wall, indicates that the mixture had no way to react in that zone.

Beyond the 200 seconds, the velocity profiles assume the parabolic shape of the steady-state laminar flow, while concentration and temperature, still under unsteady-state, always have opposite trends; in particular, the temperature increase, corresponding to the concentration decrease, denotes that all the reactant mixture passes through the reactor and reacts, with residence times inversely proportional to the velocity.

Figure 4 shows the steady-state maps of substrate concentration and temperature, for two different fluid velocities with $C_{E}=15 \mathrm{~kg} / \mathrm{m}^{3} \quad$ (a) and two different enzyme concentrations with $v_{m}=1 \mathrm{~cm} / \mathrm{s} \quad$ (b).

At steady-state conditions, with the same enzyme concentration $\left(C_{E}=15\right.$ $\mathrm{kg} / \mathrm{m}^{3}$ ), the higher the average velocity, the lower the residence time of the mixture in the reactor and, therefore, the lower the sucrose conversion and the temperature rise (top of Figure 4(a)); on the other hand, with the same average velocity of $1 \mathrm{~cm} / \mathrm{s}$, the higher the enzyme concentration, the higher the reaction rate and, therefore, the sucrose consumption and the temperature rise (bottom of Figure 4(b)). Of course, the lower the average velocity, the greater the effect of the enzyme concentration, while the higher the concentration of enzyme, the smaller is the effect of the average velocity; in other words, at steady-state, this two parameters have an opposite effect on the consumption of sucrose, so the effect of the variation of one parameter can be neutralized by varying the other. 
Finally, being the velocity profile parabolic, the central area around the tube axis $(r=0)$ is more affected by the effect of the velocity, which involves a variation of the residence time, while the area near the tube wall $(r=R)$ is more influenced by the change in concentration of the enzyme.

In Figure 5, reaction rate against substrate concentration is reported in different cases.

It can be observed that both the inhibitions reduce the reaction rate. However, whereas the product inhibition affects it at low substrate concentration, the substrate inhibition provides a stronger effect at high substrate concentration. The former can be avoided using a high substrate concentration, while the latter would require a low substrate concentration. Therefore, to better solution is to choose an intermediate value (around 300) that gives the maximum reaction rate in presence of both inhibitions.

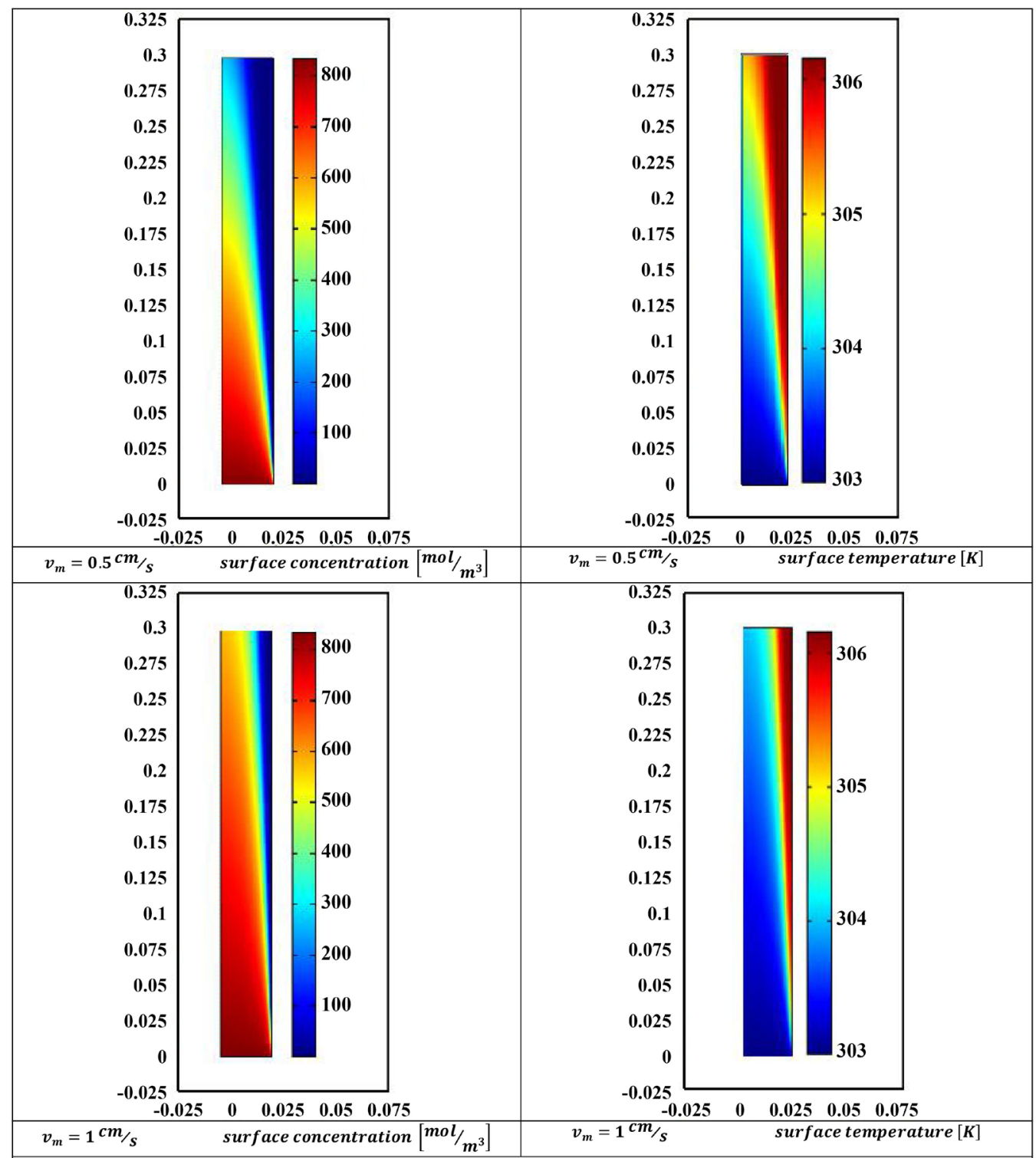

(a) 


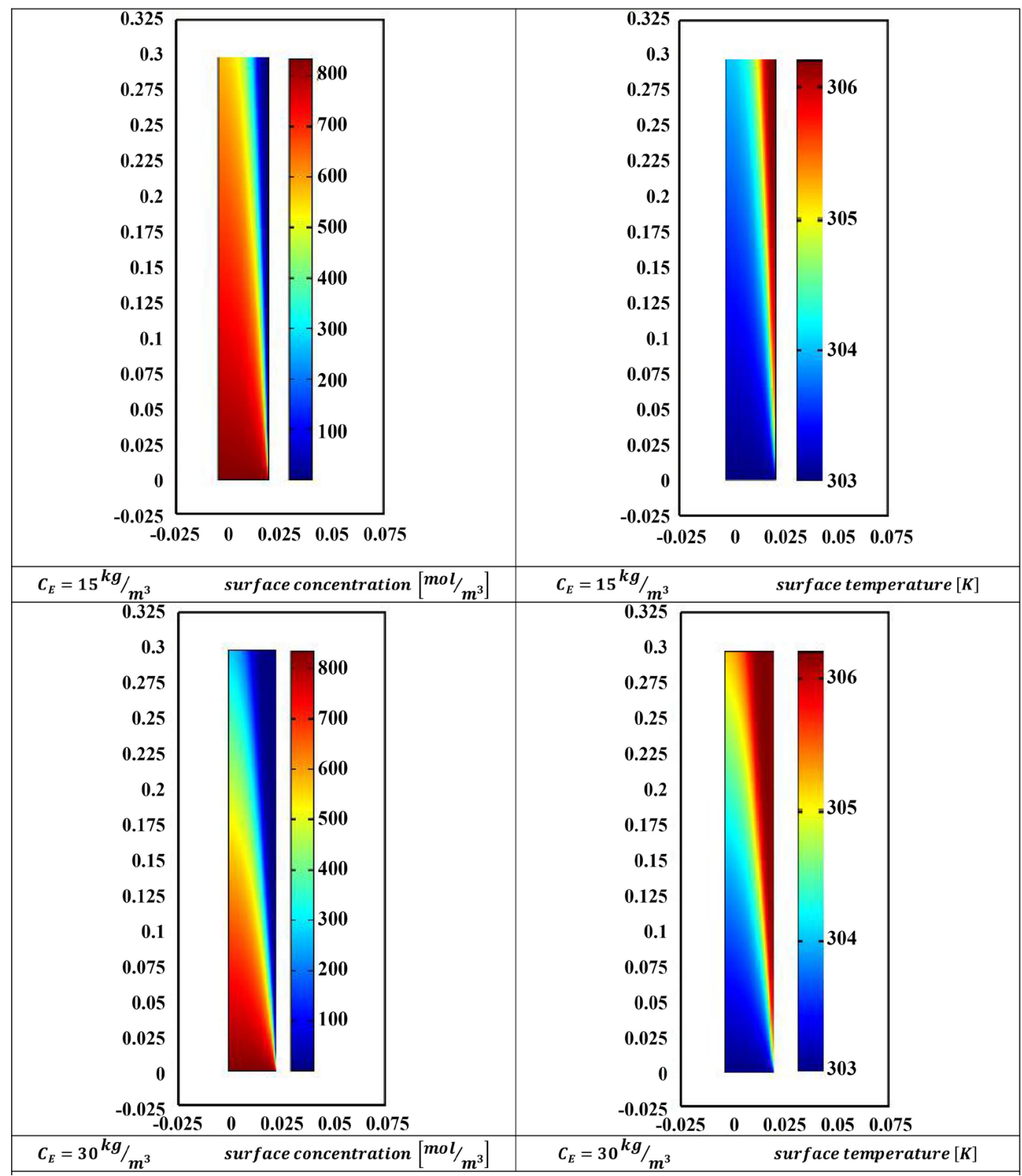

(b)

Figure 4. (a) Steady-state substrate concentration and temperature maps, varying the average velocity; (b) Steady-state substrate concentration and temperature maps, varying the enzymatic concentration.

\section{Conclusion}

A model for invertase induced sucrose hydrolysis process, with product and substrate inhibition, has been developed in a tubular reactor, varying the enzyme concentration and the reactant mixture average velocity. The simulations, obtained solving unsteady-state momentum, mass and energy balance equations, show the velocity, concentration and temperature profiles in the reactor. To correctly understand the phenomena involved it is necessary to take into account and compare all the three profiles. Moreover, enzyme concentration and reactant mixture average velocity act in an opposite way: the higher the enzyme 


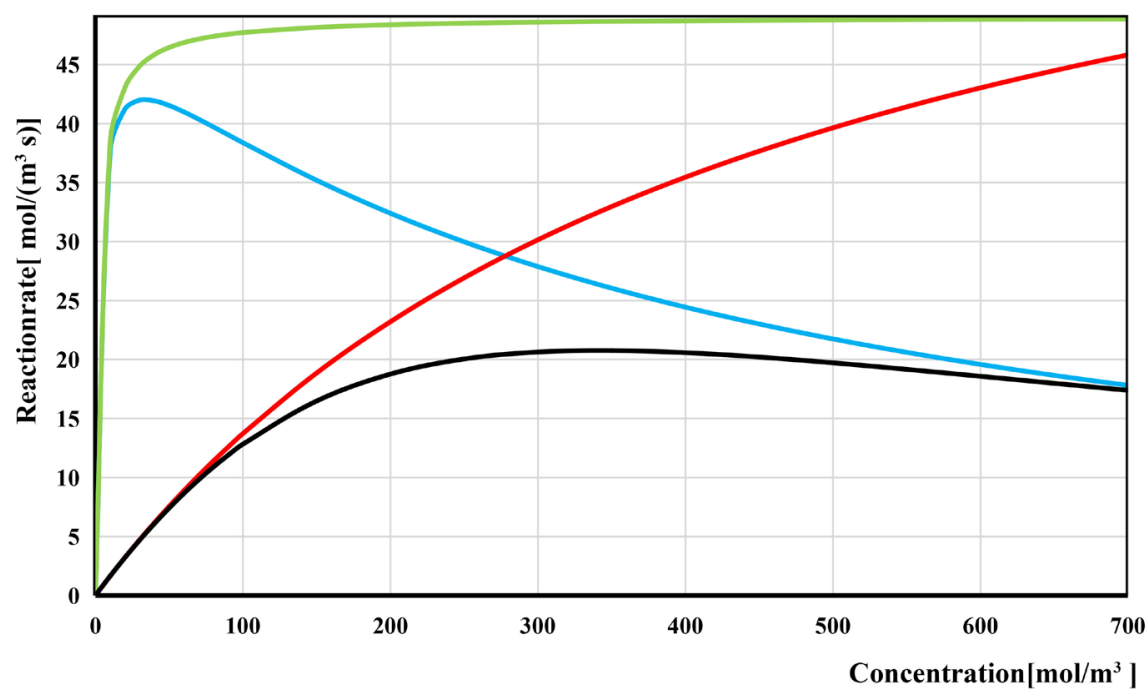

Figure 5. Reaction rate against substrate concentration in case of: No inhibition (green), Substrate inhibition (blue), Product inhibition (red), Product and substrate inhibitions (black).

concentration, the higher the sucrose conversion and the temperature rise; the higher the average velocity, the lower the residence time and so the lower the sucrose conversion and the temperature rise. Finally, to optimize the process, high values of enzyme concentration and low velocities should be used.

\section{Acknowledgements}

Authors would like to thank the University of Salerno for funding.

\section{Conflicts of Interest}

The authors declare no conflicts of interest regarding the publication of this paper.

\section{References}

[1] Queneau, Y., Jarosz, S., Lewandowski, B. and Fitremann, J. (2007) Sucrose Chemistry and Applications of Sucrochemicals. Advances in Carbohydrate Chemistry and Biochemistry, 61, 217-292. https://doi.org/10.1016/S0065-2318(07)61005-1

[2] Keramat, A., Kargari, A., Sohrabi, M., Mirshekar, H. and Sanaeepur, H. (2017) Kinetic Model for Invertase-Induced Sucrose Hydrolysis: Initial Time Lag. Chemical Engineering \& Technology, 40, 529-536. https://doi.org/10.1002/ceat.201400389

[3] Kulshrestha, S., Tyagi, P., Sindhi, V. and Yadavilli, K.S. (2013) Invertase and Its Applications-A Brief Review. Journal of Pharmacy Research, 7, 792-797. https://doi.org/10.1016/j.jopr.2013.07.014

[4] Bhalla, T.C., Bansuli, T., Savitri, N. and Thakur, N. (2017) Invertase of Saccharomyces cerevisiae SAA-612: Production, Characterization and Application in Synthesis of Fructo-Oligosaccharides. LWT-Food Science and Technology, 77, 178-185. https://doi.org/10.1016/j.lwt.2016.11.034

[5] Combes, D. and Monsan, P. (1982) Sucrose Hydrolysis by Invertase. Characterization of Product and Substrate Inhibition. Carbohydrate Research, 117, 215-228. 
https://doi.org/10.1016/0008-6215(83)88088-4

[6] Kertesz, Z.I. (1935) Water Relations of Enzymes. Influence of Viscosity on Invertase Action. Journal of the American Chemical Society, 57, 345-347. https://doi.org/10.1021/ja01305a033

[7] Bowski, L., Saini, R., Ryu, D.Y. and Vieth, W.R. (1971) Kinetic Modeling of the Hydrolysis of Sucrose by Invertase. Biotechnology \& Bioengineering, 13, 641-656. https://doi.org/10.1002/bit.260130505

[8] Goldberg, R.N., Tewari, Y.B. and Ahluwalia, J.C. (1989) Thermodynamics of the Hydrolysis of Sucrose. The Journal of Biological Chemistry, 264, 9901-9904.

[9] Bird, R.B., Stewart, W.E. and Lightfoot (2002) Transport Phenomena. 2nd Edition, Wiley, Hoboken.

\section{Nomenclature}

\begin{tabular}{|c|c|c|}
\hline$C_{S}$ & {$\left[\mathrm{~mol} / \mathrm{m}^{3}\right]$} & Sucrose concentration \\
\hline$C_{S 0}$ & {$\left[\mathrm{~mol} / \mathrm{m}^{3}\right]$} & Inlet sucrose concentration \\
\hline$C_{E}$ & {$\left[\mathrm{~kg} / \mathrm{m}^{3}\right]$} & Enzyme concentration \\
\hline$c_{P}$ & {$[\mathrm{~J} /(\mathrm{kg} \cdot \mathrm{K})]$} & Specific heat \\
\hline $\mathfrak{D}$ & {$\left[\mathrm{m}^{2} / \mathrm{s}\right]$} & Mass diffusivity \\
\hline$k$ & {$[\mathrm{~W} /(\mathrm{m} \cdot \mathrm{K})]$} & Thermal conductivity \\
\hline$k_{3}$ & {$\left[\mathrm{~mol} / \mathrm{m}^{3}\right]$} & Specific reaction rate \\
\hline$k_{m}$ & {$\left[\mathrm{~mol} / \mathrm{m}^{3}\right]$} & Michaelis-Menten constant \\
\hline$k_{\mathrm{I}}$ & {$\left[\mathrm{mol} / \mathrm{m}^{3}\right]$} & Product competitive inhibition constant \\
\hline$k_{\text {III }}$ & {$\left[\mathrm{mol} / \mathrm{m}^{3}\right]$} & Substrate inhibition constant \\
\hline$t$ & {$[\mathrm{~s}]$} & Time \\
\hline$T$ & {$[\mathrm{~K}]$} & Temperature \\
\hline$\left(-r_{s}\right)$ & {$\left[\mathrm{mol} / \mathrm{m}^{3} \cdot \mathrm{s}\right]$} & Sucrose consumption rate \\
\hline$\mu$ & {$[\mathrm{Pa} \cdot \mathrm{s}]$} & Dynamic viscosity \\
\hline$\rho$ & {$\left[\mathrm{kg} / \mathrm{m}^{3}\right]$} & Density \\
\hline$\left(\Delta H_{R}\right)$ & {$[\mathrm{J} / \mathrm{mol}]$} & Heat of reaction \\
\hline
\end{tabular}

